\title{
Afrancesamiento : l'influence française au Mexique
}

Pérez SILLER, Javier et Chantal CRAMAUSSEL (coord), México Francia.

Memoria de una sensibilidad común. Siglos XIX-XX. Vol. II. Mexico, Benemérita Universidad Autónoma de Puebla, Colegio de Michoacan, Centre d'études mexicaines et centraméricaines (CEMCA), 2004, 480 p.

\section{Dominique Fournier}

\section{(2) OpenEdition}

\section{Journals}

\section{Édition électronique}

URL : http://journals.openedition.org/transcontinentales/1423

DOI : $10.4000 /$ transcontinentales. 1423

ISBN : 978-2-8218-1410-3

ISSN : 1775-397X

\section{Éditeur}

Editions de la maison des sciences de l'homme

\section{Édition imprimée}

Date de publication : 31 décembre 2005

Pagination : 153-154

ISBN : 2200-92168-3

ISSN : 1950-1684

\section{Référence électronique}

Dominique Fournier, «Afrancesamiento : I'influence française au Mexique », Transcontinentales [En ligne], 1 | 2005, document 16, mis en ligne le, consulté le 25 septembre 2020. URL : http:// journals.openedition.org/transcontinentales/1423; DOI : https://doi.org/10.4000/transcontinentales. 1423

Ce document a été généré automatiquement le 25 septembre 2020.

Tous droits réservés 


\section{Afrancesamiento : l'influence française au Mexique}

Pérez SILLER, Javier et Chantal CRAMAUSSEL (coord), México Francia. Memoria de una sensibilidad común. Siglos XIX-Xx. Vol. II. Mexico, Benemérita Universidad Autónoma de Puebla, Colegio de Michoacan, Centre d'études mexicaines et centraméricaines (CEMCA), 2004, 480 p.

\section{Dominique Fournier}

\section{RÉFÉRENCE}

Pérez SILLER, Javier et Chantal CRAMAUSSEL (coord), México Francia. Memoria de una sensibilidad común. Siglos XIX-XX. Vol. II.

Mexico, Benemérita Universidad Autónoma de Puebla, Colegio de Michoacan, Centre d'études mexicaines et centraméricaines (CEMCA), 2004, 480 p.

1 Le groupe de recherche et d'enseignement sur les relations franco-mexicaines réunit depuis 1997 plusieurs chercheurs de diverses nationalités. Il s'est donné pour tâche d'étudier le sens et les répercussions de la présence française sur les mentalités mexicaines dans la perspective de la mondialisation. Ses activités actuelles font ici l'objet d'un deuxième tome, après celui paru en 1998.

2 Ramené au contexte de l'historiographie du pays, le projet tient le plus grand compte de la difficulté que représentent en règle générale le repérage et l'analyse des divers éléments constitutifs des sensibilités d'une population lorsqu'elle est dotée d'une longue perspective diachronique. Ou doit-on plutôt dire «des» populations, car s'agissant de l'influence de la culture française au Mexique, on ne s'étonnera pas de relever de fortes différences d'impact entre les strates sociales les plus aisées et les milieux plus populaires. En reprenant les attendus des travaux d'Alain Corbin, les responsables du projet s'interrogent sur les moyens qui permettent à l'histoire de révéler la manière dont l'individu et les groupes se voient eux-mêmes et se représentent l'Autre, se construisant ainsi un mode de perception du monde. Ils 
témoignent donc, d'une façon souvent vivante, de la volonté affichée par chaque groupe d'acteurs de construire, reproduire et transformer sa propre sensibilité en fonction d'un vécu historique différemment perméable aux influences exogènes. Le livre, en tout cas, traite de cette forme de métissage plus ou moins insidieux, en l'abordant sous des angles fort divers mais toujours cohérents: la littérature et la presse, la médecine, le commerce (c'est évidemment le plus connu, celui qui évoque les migrants de la vallée de l'Ubaye, les «Barcelonnettes»), la banque, l'urbanisme, le système éducatif.

3 On le sait, l'influence intellectuelle française doit beaucoup à une présence effective qui ne pouvait qu'être ambiguë. L'intervention politico-militaire (et scientifique) française du XIX ${ }^{e}$ siècle devait laisser des traces multiples dont l'intérêt le plus évident est qu'elles ne furent jamais totalement négatives. Le projet présenté ici s'intéresse en particulier aux communautés d'immigrants français installées dans certaines régions; un premier axe y est d'ailleurs consacré, qui pose le problème de l'articulation entre ces groupes d'origine souvent populaire et les milieux mexicains, aisés, intellectuels, qui furent traditionnellement les plus sensibles à la «culture» française. Dans ce panorama assez large, le regard croisé n'est évidemment pas oublié et il est traité en particulier à travers l'évocation des écrits des voyageurs et feuilletonistes français du XIX ${ }^{e}$ siècle, et l'impact que put avoir sur l'opinion française la prose formidable de véritables personnages de l'acabit de Gabriel Ferry et Gustave Aimard.

Une des questions principales abordées par les auteurs en fonction de leur problématique sur la mondialisation consiste à savoir si l'influence française a pu être considérée comme un agent de la modernité. Le thème n'est pas nouveau, et ce problème de la «francisation " des manières d'être (afrancesamiento) avait longuement agité les cercles intellectuels et politiques à la suite de l'accession des Bourbons au trône d'Espagne au début du XVIII ${ }^{\mathrm{e}}$ siècle, puis de l'intervention napoléonienne : le rôle de l'influence française nourrissait le contentieux qui opposait dans la péninsule deux grandes tendances politiques, voire deux écoles philosophiques. Il y avait d'un côté les gens de progrès, de l'autre les défenseurs du terroir.

Dans le Mexique d'après l'Indépendance, l'histoire se répétait d'un conflit larvé entre les principes de la tradition interne (mais laquelle, dans un pays aux multiples dimensions ethniques?), et les éclats d'une modernité venue de l'extérieur, tout particulièrement d'un pays marqué par les Lumières d'abord, le rationalisme ensuite. Car les conséquences d'une ouverture des sensibilités vers un autre monde ne pouvaient qu'être mises en balance avec la logique d'un pouvoir politique à peine consolidé, soucieux de s'appuyer sur une idéologie fondée sur la pérennité d'une culture traditionnelle sans cesse réinventée. N'oublions pas en effet que les mentalités mexicaines autochtones ont toujours fait preuve d'une disposition particulière au métissage culturel parce qu'elles ont été influencées depuis des siècles par un appareillage idéologique "panaméricain » fondé sur un système de transformations qui érigeait l'adoption en principe fonctionnel majeur, même en matière de parenté.

6 L'ensemble des textes inclus dans l'ouvrage est édité en espagnol. S'il fallait justifier cette option, on rappellerait que l'ensemble des collaborateurs du groupe de travail, même ceux qui sont d'origine française (deux), appartiennent à des institutions mexicaines ou nord-américaines. Chaque chapitre fournit une quantité de faits, d'informations et d'analyses qui nous permettent de porter un regard renouvelé non seulement sur la présence française au Mexique, mais aussi sur l'évolution de l'histoire 
et de la culture de ce pays. À l'évidence, les enseignements d'un tel livre, rapportés au constat d'une attirance plus ou moins forcée de celui-ci vers sa frontière septentrionale, nous font appréhender l'importance des liens intellectuels qui unissent le Mexique et la France depuis longtemps, et il devrait contribuer à relancer une volonté de partager des opérations originales beaucoup plus nombreuses dans les domaines de la recherche et de l'université. On regrettera seulement que, couverture et typographie exceptées, la réalisation matérielle du volume, revendiquée par trois éditeurs, ne soit pas des plus exemplaires, bien moins satisfaisante que d'autres (coéditions ou non) émanant du CEMCA, et en particulier celle du tome antérieur, daté de 1998.

\section{AUTEURS}

\section{DOMINIQUE FOURNIER}

CNRS-UMR 5145 «Éco-anthropologie » 